\title{
The Structural Violence of Patient Participation in Cambodian HIV Services
}

Qualitative Health Research

$1-12$

(C) The Author(s) 2015

Reprints and permissions:

sagepub.com/journalsPermissions.nav DOI: $10.1177 / 1049732315583269$

qhr.sagepub.com

\author{
Eve Bureau-Point' and Sovannoty Phan'
}

\begin{abstract}
Participation of people living with HIVIAIDS (PLHA) has become a new standard of good governance in HIV services worldwide, and most HIV organizations make reference to it. This standard has had a considerable impact in Cambodia, where hundreds of PLHA have been recruited by organizations to participate in the development of HIV services. However, participation is a vague concept with various interpretations and applications. Drawing on ethnographic research conducted between 2006 and 2008, this article first clarifies what promoters expect from patient participation in Cambodia and then examines its meanings and uses for one category of PLHA working in hospitals (hereafter "volunteers"). It shows that volunteers have played a valuable role in the scaling-up of access to care and treatment policy, and that although international organizations in Cambodia see patient participation as empowering PLHA, these volunteers face structural violence caused by inherent conflicts within Cambodia's strict health care hierarchy.
\end{abstract}

\section{Keywords}

HIV/AIDS; Asia; Cambodia; participation / social; power / empowerment; community and public health; human resources; ethnography; relationship / health care; qualitative

At the beginning of the AIDS epidemic in the 1980s, governments' lack of response to the increasing number of deaths in the gay community spurred community network of people living with HIV/AIDS (PLHA) in North America and Western Europe to demand and obtain the possibility to become actors in the decision-making processes in related political, pharmaceutical, medical, and scientific arenas (Barbot, 2002; Epstein, 1998; Nguyen, 2010). Little by little, policy makers began to consider PLHA and non-governmental organizations (NGO) as essential partners.

PLHA participation was progressively included in documents such as the Greater Involvement of PLHA (GIPA), whose key principles are to fully involve PLHA in decision making as well as formulating and implementing HIV/AIDS policies (United Nations Program on HIV/AIDS [UNAIDS], 1999). The Declaration of Commitment on HIV/AIDS of the United Nations General Assembly Special Session on HIV/AIDS (UNGASS; 2001) expressed its strongest support for GIPA. Since the mid-2000s, patient participation has continued to be formalized in recommendations and programs, especially for low-income countries with understaffed facilities. One example is the World Health Organization's (WHO) task-shifting recommendations for HIV/AIDS care, which are based on the principle of delegating tasks from highly qualified health workers to health workers with less training and fewer qualifications, thereby "placing strong emphasis on patient selfmanagement and community involvement" (WHO, 2006, 2007). Established on this task-shifting principle, "expert patient programs" have been implemented in Malawi, Swaziland, Mozambique, and Lesotho. In these programs, PLHA participate in health promotion, prevention, care, and/or treatment activities. Accordingly, patient participation as part of the response to HIV has become institutionalized in many policies, and has developed into a global standard which most HIV organizations make reference to.

In Cambodian HIV services, which are for the most part technically and financially supported by international organizations, these principles have received considerable attention. Since the mid-2000s, most national and international organizations in Cambodia have promoted patient participation and hundreds of PLHA have been recruited by them. They are responsible for multiple tasks in the development of HIV response activities.

'Aix-Marseille University, Marseille, France

Corresponding Author:

Eve Bureau-Point, Aix Marseille University, UMR 912, Institut de

Recherche pour le Développement, 23 rue Stanislas Torrents, 13006

Marseille, France.

Email: evebureau23@yahoo.fr 
PLHA participation is part of a longer established phenomenon of involving "ordinary citizens" in patient care. Such initiatives have existed in one form or another in the health policies of low-income countries since the Alma Ata conference, where the participation of populations was placed at the heart of primary health care policy (WHO, 1978). Thirty years of literature covering this theme-which we will term "lay participation" in this article - highlight that lay participation policies are generally not well-defined and include a multitude of meanings which vary widely depending on the context (Green, 2000; Morgan, 2001). Meanings are sometimes ambiguous (Cooke \& Kothari, 2001; Mosse, 2004) or contradictory (Bureau, 2013; Marsland, 2006), with implementation often failing to meet initial expectations (Campbell \& Cornish, 2010; Dudley, 1993). The literature also highlights that in other participation contexts lay participation is above all synonymous with "empowerment" (Marsland, 2006; Morgan, 2001). This in vogue Anglo-Saxon concept literally means "strengthen and acquire power." It refers to the idea that lay people are recognized as individuals with authority who are capable of negotiating. In this way, as highlighted by Fox, Ward, and Rourke (2005), empowerment challenges established power structures in society.

In this article, we first propose to clarify what the representatives of national and international HIV organizations promoting PLHA participation in Cambodia expect from this policy and then to examine its application by describing the roles and experiences of one category of PLHA working in hospitals in the country, locally referred to as "volunteers." This work not only complements initial studies on lay participation in the Cambodian context of HIV (Aveling, 2010; Paxton \& Stephens, 2007) but also provides in-depth ethnographic insights into the hitherto undocumented specific contribution, immersion, and experience of PLHA workers in the Cambodian context.

\section{A Brief Presentation of Cambodia and HIV in Cambodia}

In 1970, Cambodia was plunged into chaos for two decades. During the military regime of Lon Nol between 1970 and 1975, Cambodians were embroiled in the Vietnam war. Between 1975 and 1979, the Khmer rouge regime was responsible for the deaths of approximately 2 million people, ${ }^{2}$ including intellectuals, such as physicians, professors, and Buddhist monks who represented moral authority. In 1979, Vietnamese forces invaded Cambodia, ostensibly to liberate the country from the Khmer rouge, and controlled it until 1989. The launch of the United Nations peacekeeping operation in 1991 marked the beginning of a transition from a closed socialist system to a capitalist open-market one, where new global standards originating from Western democracies began to circulate, cohabit, and become entangled. Tourists slowly started coming to Cambodia and a plethora of international NGO established themselves in the country. During this time, the Cambodian government was primarily preoccupied with setting up policies and programs to deal with foreign investment, landownership, and new entrepreneurship (Bith-Melander, 2005).

Cambodia has the highest national prevalence rate of HIV/AIDS in South-East Asia, the peak prevalence being estimated at $2.8 \%$ in adults between 15 and 49 years of age in 2002 (Kimerling et al., 2002). The main route of transmission is heterosexual, linked to the practice of having multiple partners, which is widespread in Cambodian society. Unlike China, where the government denied the existence of HIV/AIDS for many years (Micollier, 1999), Cambodia responded rapidly to the epidemic, with the support of bilateral and multilateral organizations. The government set up the Cambodian AIDS program in 1993, 2 years after identification of the first case of HIV infection. In 2007, approximately 100 organizations were involved in the HIV services sector (HIV/AIDS Coordinating Committee [HACC], 2008). The majority were recipients of the Global Fund. One of the principles of this financing is the reinforcement of government capacities, entrusting, when possible, the management of Global Fund financing to national AIDS programs. This is the case with Cambodia. Although Michaud wrote in 2005 that the representatives of humanitarian organizations in the country, in general "work independently, often with little interaction with each other or with public health services" (Michaud, 2005, p. 22), in the context of HIV, the Cambodian AIDS program has had more control over the sector's actors and activities. This is directly linked to the arrival of Global Fund financing, antiretroviral treatments, and the establishment of a national guideline for a continuum of care, ${ }^{3}$ which must be adhered to by every organization to receive funding. At the time of the present study, most HIV organizations were working in the public sector, their activities reflecting for the most part the recommendations set out in the Cambodian AIDS program. In 2007, 51 sites offering continuum of care were open in 21 of the country's 24 provinces (National Center of HIV/AIDS, Dermatology and Sexually Transmitted Diseases [NCHADS], 2008). International aid workers were present on a daily basis in 10 of these sites. In the other 41 sites, their presence was much less frequent, only a few visits being made every month. Although greater technical program autonomy was observed between 2006 and 2008 , this was minimized by strong financial dependence on international donors. In $2010,97 \%$ of the resources for the Cambodian AIDS program came from external donors (National AIDS Authority [NAA], 2010). 


\section{Research Design and Methods}

This anthropological study, performed during four field missions between February 2006 and April 2008, ${ }^{4}$ was nested within a larger study titled "The Roles, Challenges, and Impacts of the Participation of People Living With HIV/AIDS in the Control of the Epidemic in Cambodia" (French National Agency for AIDS Research [ANRS] 12133). ${ }^{5}$ For the larger study, four Cambodian researchers conducted sociological research on different aspects of participation of PLHA in HIV care including the participation of women, civil disobedience, ${ }^{6}$ participation of drug users, and participation with the purpose of benefitting from access to health insurance. ${ }^{7}$

Data from the nested study were collected by BureauPoint in close collaboration with a Cambodian research assistant, Sovannoty Phan, who was trained in qualitative research methods in social sciences. We first familiarized ourselves with the network of actors in HIV/AIDS in Cambodia to identify the different categories of potential informants active in the promotion and implementation of patient participation, as well as those who preferred to distance themselves from it. The following categories were identified: PLHA workers, routine health personnel who worked with PLHA workers, and users of HIV services and health planners from national and international organizations who design and coordinate HIV services. Hospitals were chosen as the primary location to make contact with these different categories of informants, as they constitute the gateway to accessing the full range of inpatient and outpatient services provided. The following range of factors, used to define inclusion criteria, ensured we made contact with a wide range of informants: (a) age, (b) gender, (c) role, and (d) place of work. The following 42 different study locations were included: 4 hospitals (1 in the capital Phnom Penh and 3 in the provinces of Battambang, Kandal, and Siem Reap), a total of 11 headquarters of PLHA networks and of national and international organizations working in the fight against AIDS, 7 conference rooms where governmental national AIDS policy was discussed, and the homes of 20 patients where support groups were organized and where home-based care was provided.

Several research methods were used in the nested study presented here. First, ethnographic interviews were conducted with 157 participants from different informant categories as follows: 87 PLHA workers (38 women and 49 men, aged 20-60, comprising 20 volunteers, 14 counselors, 12 Mundul Mith Chuy Mith ${ }^{1}$ [MMM] coordinators, 15 staff members from HIV organizations and PLHA networks, 12 self-help group leaders, and 14 home-based care leaders); 30 health planners (aged 25-69, comprising 15 international workers from international organizations and 15 staff members working in the Cambodian national AIDS program and in local NGOs); 20 routine health personnel (aged 27-55, comprising 8 physicians, 8 nurses, and 4 hospital directors); and 20 users of HIV services (aged 19-63). The following main topics were considered in the interviews with the 87 PLHA workers: history of their participation in HIV care services; motivation to participate in the HIV health care system; expert and lay knowledge acquisition processes, specific duties, advantages and disadvantages of working in this field; and the personal and collective impact that participation had on them. With respect to the 50 health planners and routine health personnel, we examined the following topics: their views with regard to PLHA participation and their actions either to support or prevent it. Some interviewees in each informant category were interviewed 2 or 3 times during the study to understand the evolution of their views on patient participation. ${ }^{8}$ The interviews lasted 30 to 90 minutes and were conducted by the first author, with the second author working as an interpreter from Khmer to English. Most of the interviews with PLHA workers and routine health personnel were conducted in Khmer. The majority of interviews with health planners were conducted in French or English. All interviews were recorded with the agreement of the interviewees and were transcribed. Interviews in Khmer were translated and transcribed into English by the second Author.

Other research methods used included direct observations (a total of 50 observation sessions were performed at national conferences, support-group meetings, workshops, internal meetings of NGOs, PLHA network meetings, and health education sessions in hospitals), and in-depth examination of official documents (Cambodian National AIDS program and various NGOs' guidelines and reports). During each direct observation session, which lasted 1 to 6 hours, we took field notes about how actors reacted to the theme of patient participation.

The different types of data were progressively collected. Each interview was analyzed separately, using a thematic approach, and iterative and cross-reading procedures, until each of the themes selected had been completely covered. The data collected were coded into four main themes: (a) diverging views of patient participation, (b) the heterogeneity of the roles attributed to PLHA workers, (c) the benefits of participation for PLHA workers and the health system, and (d) the structural violence faced by PLHA workers resulting from strict local hierarchy. The first author coded the material. The results were checked for accuracy by the second author. Our results were discussed with the other researchers involved in the larger study twice a year. Data saturation occurred in 2008, when the investigators had a sense that there are no new directions to be explored and when little or no new information was being obtained during observations and interviews (Olivier de Sardan, 1995). Using Grounded Theory techniques (Corbin \& Strauss, 2008; Glaser \& 
Strauss, 1967), research problems and questions were reoriented when primary analysis from the data collected suggested that this course of action was beneficial for the study. More specifically, although the initial objectives of the nested study were to investigate the construction of expertise in patients, intermediate results led us to focus more on the theme of hierarchy and structural violence.

The study was approved by the National Ethics Committee for Health Research (NECHR) in Cambodia in March 2006. Ethical issues, including recruitment and data collection processes, informant consent, protection of participant privacy, and data storage, were included in our approved proposal. All participants received information about the study and provided written consent to participate. All data were anonymized and participant names used in this article are pseudonyms.

\section{Findings}

\section{Health Planners and Patient Participation}

In the strategic documentation of HIV organizations in Cambodia, phrases like "PLHA must play an active role in the development of programs which concern them," "they must be involved at all levels in health care," "they must be active in the community," and "the community, including PLHA, plays an important role in the support activities for PLHA" are omnipresent. However, what one is to understand precisely by "important role" or "active role" remains unclear. Not only are the reasons for implementing these ideas not discussed, how the latter might be implemented is not specified in concrete terms.

Observations and interviews with different health planners highlighted that most generally consider PLHA workers as human resources who strengthen the health system by performing multiple tasks using key knowledge and know-how which routine health personnel do not have. The following accounts by Isabelle and Sopheap, health planners in an international and national organization, respectively, illustrate this:

PLHA will be increasingly needed, as the 45 centers which are currently open will, inevitably, never have enough nurses to ensure adequate support, research on lost-to-follow up patients, education about adherence, and so forth. PLHA act as a bridging point between the sick and caregivers. When they move from consultation services to radiology departments [for example], sometimes patients are weak, they don't know where the department is located, and so the PLHA accompany them. They do all this work, which is kind of social, and is something one would never ask a qualified nurse to do. Moreover, they [the nurses] are not motivated enough, they never make enough time in their work timetable to do this. And well, you see, you need people who are sufficiently socially open, and who have a little empathy with others. (Woman, 46 years old, International Health Planner A)
Sopheap explains the role of one of the PLHA working in the HIV service he coordinates:

He does a lot in terms of group facilitation. For training, he presents, sometimes he substitutes for me. Because I take care of everything and it's a little difficult, above all I have time constraints, I cannot participate in all training, in all workshops. He represents me at some meetings, so he is indispensable. (Man, 44 years old, National Health Planner D)

Arguments more specific to the Cambodian context also surfaced during interviews to justify patient participation. In a country where the public sector is considered not only costly and corrupt, because of the need to give bribes at many levels of care, but also inefficient, because of the lack of medical equipment, knowledge and deontology, patient participation is considered as a means to make health structures more attractive to patients in general. One international health planner reported that he recruited PLHA to improve the relationship between the patients and the hospital:

Before, it was the case that the sick person was the dog and the doctor the master, the patients had nothing to say, and besides, patients who had no more money to buy ARV [antiretroviral] were embarrassed about going to see their doctor ... A patient who is a counselor, well that patient is going to follow what you say better, he's going to understand better, have greater trust, just that, you're going to multiply the quality of care by 10 . (Man, 38 years old, International Health Planner F)

Although promoters of patient participation in Cambodia agree on the utility of PLHA participation as a human resource to improve the offer of care, two distinct approaches to such participation surfaced in our observations and during interviews with national and international promoters: One was lay-centered, based on the idea of empowerment, advocated in large part by the representatives of international organizations, whereas the other was centered on the country's public health system, defended for the most part by local organizations.

In one provincial hospital, patients were utilized with the goal of creating an autonomous patients' group within the hospital to propose support activities to other patients. Three international workers were recruited to implement this project. Here is what Laila, a nurse with an international organization, had to say about the project:

After our 2 years of work, the project was completely in pieces. We realized that we were 10 years too early with our ideas so we just dropped everything. If nobody is behind pushing them, they don't do anything! So we said to ourselves that in the end they really didn't want this patients' group, or that they hadn't the right profile for this. They have no spirit of initiative, maybe they don't have the desire, they 
are afraid. We dropped everything and in the end what we do now is directly manage them. (Woman, 41 years old, International Health Planner $\mathrm{H}$ )

A similar, more successful project exists in a hospital in the capital Phnom Penh, despite the fact that the patient association there has never fully stood on its own two feet, which was something the representatives of the international organization who pushed for its implementation would have liked. It has always been financially and technically dependent on international workers. Supervised by a representative, who is one of the few local HIV activists in the Cambodian context, eight employees and three volunteers carry out self-support and adherence support activities in the hospital. In daily interactions, the project's international workers encourage the representative to develop a new working culture, based on the principle that all forms of non-respect of patients created within existing structures must be contested. They regularly finance international trips for the representative to countries where she is introduced to renowned international activist networks. At numerous national and international conferences, she has also been encouraged to speak out about problems Cambodian patients have which are rarely touched on in public, including the irony of "free" access to treatments, and land evictions, which many PLHA, among others, have been victims of.

When we interviewed representatives of influential national organizations, they rarely talked about empowerment. Only one, Seng, said that he would like PLHA to have more control over activities. Nevertheless, he doubted their abilities:

You see, with patients, I have never been able to observe democratic participation. Patients are not very welleducated, they are shy about speaking in public. Us, our principle, is that we want them to express themselves, we want their voices to be heard. (Man, 52 years old, National Health Planner B)

However, most of the time a utilitarian vision, or better still, a power-based vision, dominates the words and intentions of local health planners. The words of Rasmey and Visal, representatives of national organizations, illustrate this:

PLHA work every day from 9 to 5; they stay all day and do menial jobs. For example, if a patient needs to be accompanied, a volunteer will take him to the consultation. His role consists in helping the professionals working in the hospital, talking with patients in the waiting room and guiding them to the different places they have to go to. (Man, 50 years old, Health Planner E)
Table I. Interviewee Volunteers' Demographic Data.

\begin{tabular}{lccr}
\hline Demographics & Variable & Total & $\%$ \\
\hline Gender & Man & 9 & 45 \\
& Woman & II & 55 \\
Level of education & Primary & II & 55 \\
& Second level & 8 & 40 \\
& Third level & I & 5 \\
Age at Ist interview & $<25$ & 1 & 5 \\
& $25<35$ & 9 & 45 \\
& $35<45$ & 8 & 40 \\
Year of Ist interview & $45<55$ & 3 & 15 \\
& 2006 & 11 & 55 \\
Year of 2nd interview & 2007 & 9 & 45 \\
& 2006 & 2 & 10 \\
Year of 3rd interview & 2007 & 8 & 40 \\
& 2008 & 2 & 10 \\
\hline
\end{tabular}

In his interview, Visal shared his vision of the attitude which government staff have about civil society representatives: "PLHA have the right to speak but we have the right not to listen" (Man, 40 years old, Health Planner G).

We are now going to see how patient participation, which health planners approach in a different fashion, came into practice in Cambodian hospitals, by describing the roles of volunteers and the way they experience their work.

\section{The Roles of Volunteers in Cambodian Hospitals}

We describe the activities of a woman who we call Pisey, to illustrate the diversity of roles PLHA workers play inside hospitals. Pisey's roles reflect those undertaken by most of the other volunteers interviewed in this study (for other volunteers' demographic data, see Table 1). In the majority of HIV care services, an average of three to four volunteers are recruited. She was one of the four volunteers working in a provincial hospital mainly managed by local players. ${ }^{9}$ When first interviewed in 2006, she was 30 , married, and had a 5-year-old daughter. She was in relatively good health and had worked at the hospital as a volunteer for 2 years. She had been on antiretrovirals for a year and was being followed-up in the same hospital.

First, her participation required her constant presence in the hospital. She was the first member of the medical team to arrive and the last to leave. She undertook administrative tasks usually performed by nurses at reception, registering patients when they arrived and preparing their medical files for physicians. She was often asked by routine health personnel to go fetch people, information and material, to take samples to the laboratory, to transfer patients to other services and to clean. She also took on 
the duties of an auxiliary nurse, a socio-professional category that does not exist in Cambodia. Usually, families take on this role, assuming day-to-day tasks for hospitalized patients, such as providing meals, washing them, dressing them, and giving them moral support. Many PLHA become destitute because of stigmatization. Pisey provided care to these socially isolated patients. This is how she described her work with these patients

I go to their bedside. I ask them if anything is wrong, if they need something. I help them to wash themselves, wash their clothes, take their medicine, eat. Sometimes, they give me money to buy something they need. I take them to the shower when they can't move. I clean them after they've been to the toilet. I assist the nurse. (Woman, 30 years old, Volunteer A)

In addition to these activities, she was also a facilitator. She would go round the waiting room and answer questions that patients had about hygiene, nutrition, drugs, and prevention. She also guided patients when they were lost in the hospital. She conducted face-to-face and group counseling to ensure that patients understood how HIV is transmitted, how to take their treatment and how to take care of their health. She also introduced them to support groups, home-based care teams, and NGOs. She facilitated the referral of patients to different services and the diffusion of health information.

She was regularly invited to attend workshops and training sessions on counseling, HIV care, and advocacy techniques - usually in Phnom Penh - to ensure that her knowledge on HIV care was up to date.

\section{Benefits of Patient Participation for Volunteers}

When first interviewed, volunteers mentioned health benefits for themselves, such as direct access to caregivers and to advice. With regard to acquiring new information about self-management of health, volunteers find themselves in pole position. They feel less isolated, they are happy to help their peers, and by working they avoid inactivity which can be a source of anxiety and depression.

I'm happy to work as a volunteer here. If I'm sick, I receive treatment on time and second, I can help other PLHA avoid the feeling of hopelessness. If I stay at home, I get anxious because of concerns about HIV, I'm not in a good mood, so when I work here, I'm in a good mood. Moreover, I meet many PLHA here. I can help us all and I feel happy about that. (Woman, 28 years old, Volunteer L)

Through this job, first of all, I got knowledge about HIV/ AIDS, and with this experience I educate other PLHA and afterward they can spread this knowledge to other PLHA in their communities. When I face many new cases, my knowledge increases and I feel motivated to work because it's not only me who has this problem, other people have the same problem. (Man, 42 years old, Volunteer $\mathrm{H}$ )

The main positive impact Pisey highlighted when first interviewed was, "I keep busy by working so I can forget about my status" (Woman, 30 years old, Volunteer A). Both personal and collective interests were underlined by volunteers when first interviewed.

\section{Disillusion, Precariousness, and Ambiguity of Volunteer Status}

After some months in these positions, most volunteersalbeit rarely openly complaining - showed their disillusionment in interviews, with respect to the precariousness, fatigue, exhaustion, and feeling of exploitation which they faced, as illustrated by the following account provided by the volunteers. Pisey, the volunteer whose different roles we described above said,

Sometimes I work during the night, but I don't know if I'll be able to do so for long, because I'm sick too. The income is always the same, US\$30 per month, but the workload increases every day. An average of 2,000 patients are followed up in the hospital, and preparing their medical files makes me dizzy. The NGO should give us a suitable salary. How can a salary of US\$30 for a full-time job be moral? (Woman, 31 years old, Volunteer A)

Sovath said, "For me, it is discrimination, PLHA must receive equal salaries to those of seronegative persons, because we work 5 days a week like the others, and because we do just an important a job as they do" (Man, 42 years old, Volunteer H). Saroeun reported, "Volunteers who work with PLHA get very low salaries compared with the permanent staff. In reality, volunteers work harder than the staff" (Woman, 27 years old, Volunteer J).

When volunteers compare the small sums they earn with their daily workload and the energy they put into their work, they become disenchanted and would like to become a staff member or leave as soon as possible to find a better paid job. Viseth said, "I don't want to be a volunteer all my life. I don't say it openly, but I hope to be recruited as a full staff member of an NGO" (Man, 36 years old, Volunteer M). Sovath explained, "From my observations, all the volunteers working in the hospital expect that they will be given a real salary and that the hospital will give them staff positions, because we don't want to remain volunteers forever" (Man, 42 years old, Volunteer $\mathrm{H}$ ).

At the time of this study, volunteers were paid an average of US\$30 per month which was close to that of civil servants (US\$40). Nevertheless, their situations are different: Civil servants have access to certain benefits and networks of relationships that facilitate lucrative parallel 
activities. Volunteers have no such access. Most come from poor families and live in conditions of hardship. They find it difficult to make ends meet on a daily basis, as Tida illustrated: “I don't think about my future because I regularly get sick and I only think about how to take care of my health to find food for my children. I care only for my children nowadays" (Woman, 28 years old, Volunteer O). Bunny said, "Volunteers just work to work, I mean they work to earn money to feed their families" (Woman, 30 years old, Volunteer C). Other volunteers summed up the situation very succinctly: "Most people want to help others, but first of all they have to help themselves" (Volunteers H, J, and R).

Furthermore, volunteers have no job descriptions outlining their responsibilities and therefore have no control over their work, exacerbating the precariousness of their jobs.

As a volunteer, I didn't have contract. For me, I would like to have a contract because it gives me work stability, and nobody can fire me when they want without having a reasonable motive, and right now without a contract, I don't know when they'll fire me. As a matter of fact, they can do that whenever they want because I don't have any contract. (Woman, 28 years old, Volunteer L)

Moreover, by doing these jobs, volunteers are implicitly disclosing their serostatus. In the general Cambodian context, when PLHA have a choice (especially in the case of the rich and middle classes), they do not disclose, to avoid discrimination and its social consequences on their family's reputation and on their other networks of relationships. Thol said, "Mostly, for the patients who aren't poor, they do not disclose their status, and they don't want support from the NGO (Man, 36 years old, Volunteer T)." This partly explains why most volunteers are poor.

\section{The Inherent Conflicts in the Health Care Hierarchy}

International promoters of patient participation expect volunteers to gradually reach positions of power and be able to negotiate with routine health personnel and health planners. In Cambodia however, once volunteers enter hospitals, most remain at the bottom of the social ladder and submit themselves to the existing hierarchical system in which health planners, physicians, nurses, and administrative employees exercise authority over them and confine them to menial roles. The two following quotations illustrate this behavior of submission to the hierarchy, which is very prevalent in volunteers:

You have to learn to obey the doctor. I'm under orders at the hospital. When the doctors ask me to do something different from what I usually do, even if it's not linked to my work, I have to do it. It's tiring. I don't have the right to refuse what I'm ordered to do. (Woman, 32 years old, Volunteer Q)

Khim reported, "In this hospital, besides me, nobody wants to speak about the problem, they are afraid of being fired" (Man, 46 years old, Volunteer B). In general, volunteers do not feel at ease and do not feel accepted by the health care system. They do not trust routine health personnel or national health planners. They are afraid of losing their job if they stray off the track. Tida reported, "In front of me, there is no problem but behind my back I don't know whether they gossip about me or not" (Woman, 28 years old, Volunteer O). Chenda said bluntly, "I don't trust khmer doctors" (Man, 49 years old, Volunteer S). One international health planner trying to develop PLHA worker empowerment said, "Take all the seropositive people who work with us, all of them think they're being looked down on!" (42 years old, International Health Planner B). Volunteers often feel discriminated against, as illustrated by the following quotation: "When I worked at the hospital reception, everyone blamed me, when a medical record was misplaced I was always the one at fault" (Man, 40 years old, Volunteer D).

When the few volunteers who did take initiative defended their point of view and tried to be influential, they were always reminded (directly or indirectly) of their social origin and position. They faced social pressure through intimidation and abuse of power. Many volunteers explained that being often asked by an international NGO to go to workshops, round-table meetings, and conferences, and expected to participate in decision making, put them in a paradoxical situation, and that in reality they could not actively participate in such meetings. One of the consistent complaints volunteers brought up in interviews was that they were never listened to when they dared to speak publicly. This is how Somaly described health planners' strategies to ensure she kept quiet: "The government did not allow me to show my PowerPoint presentation and told me to say good things about the government" (Woman, 41 years old, Volunteer P). Moreover, as a way of opposing the introduction of volunteers into hospitals, some physicians discredited the former's work in consultations and did not refer patients to therapeutic education sessions which volunteers were supposed to facilitate. Volunteers also reported that they had been threatened with removal or discontinuation of treatment after engaging in anti-corruption lobbying with patients, whereby they explained to the latter that consultations were free of charge, and that patients should not give care providers any bribes. Volunteers also described controlling strategies, developed by the local elite, such as the appointment of pro-establishment PLHA to head patient networks. These PLHA were effectively HIV representatives who would apply the recommendations of 
the authorities and not take into account ordinary PLHA claims, despite the fact they officially represented the latter. These examples of social pressure show how volunteers, despite their desire to change the hierarchical order themselves, are confined to performing menial tasks, at the bottom of the hierarchy of care provision and organization.

PLHA workers remain at the bottom of the social scale, but this does not mean they are passive. Some decide to no longer openly say that they live with HIV and instead allow themselves to be called krupet (physician in khmer) by other patients, as the latter do not always know the status of workers in care structures and use this term out of politeness. PLHA workers who make this choice turn their backs on one important public health objective of patient participation which is to shorten social distance between patients and health care structures. Other PLHA workers engage in corruption, reproducing the practices of other professionals. Although this might be seen as a form of empowerment, it is not the kind of empowerment originally envisaged by international health planners.

\section{Discussion}

This study highlights the specific meaning and application of the worldwide patient participation HIV policy, developed in the 2000s, in the specific context of Cambodia. It underlines the invisible and invaluable work performed by PLHA workers in the development of HIV services in Cambodia between 2006 and 2008, and the inherent conflicts within the strict health care hierarchy, which constitute a root cause of structural violence for PLHA.

PLHA hospital "volunteer" workers perform administrative, logistic, and social duties which are key elements of the national HIV/AIDS policy. They provide other PLHA with a great deal of information about the virus, its symptoms, treatment, side-effects, follow-up, social networks, and therapeutic itinerary. In this way, they share essential information on treatment adherence and participate in increasing access to care and treatment. They reduce the workload of routine health personnel by doing tasks previously performed by the latter. All this reflects a change in how the patient is perceived by health planners, with PLHA no longer being considered passive, but rather actors who possess lay expertise. Because of their knowledge acquired through experience, PLHA can become a key intermediary for conveying information about the illness, understanding other PLHA needs, providing patient-tailored advice, and facilitating communication between caregivers and patients. In Cambodia, the practice of using patient participation in hospitals started when the strategy of decentralizing centers for access to care was first established by the Cambodian AIDS Program in 2004. The WHO "3 by 5" objective was reached, in which antiretroviral treatments were distributed to 10,000 PLHA before the end of 2005. The strategy was continued later. In 2005, approximately 25 access sites were open (Médecins Sans Frontières [MSF], 2006), this number increasing to 51 in 2008. PLHA workers certainly contributed to this scaling-up of access to care and treatment policy. Furthermore, the use of volunteers lowered health costs (Lehmann, Van Damme, Barten, \& Sanderset, 2009) and built what it is called in the language of development "sustainable programs." As patient participation is an essential criterion when seeking funding, the presence of volunteers made it possible for HIV services to ensure conformity with good governance of the HIV epidemic, and to ensure the continuity of donor support. As of today, their work has never been documented and recognized as key in the implementation of the national AIDS policy. Only vague, short allusions to volunteers' contributions have been made in the literature (Morineau et al., 2009; Sopheab, Fylkesnes, Lim, \& Godwin, 2008).

However, the personal experiences of volunteers in this study showed a darker side to patient participation for PLHA volunteers themselves. Despite some initial benefits, once established in their positions, they had the feeling of being discriminated against and being exploited by health planners and routine health personnel. This study highlighted the rigid health care hierarchy in Cambodia, which impedes PLHA workers from playing the role expected of them. Although patient participation was originally centered on PLHA empowerment, in Cambodia it is currently synonymous with domination, contradiction, and reproduction of the social order. In that sense, we can use the concept of structural violence to qualify volunteer experience of participation. The concept of structural violence, alluding to "indirect forms of violence built into social structure which prevent people from meeting their basic needs or fulfilling their potential" (Galtung, 1969), was used by Farmer (2003) to broaden the explanation of disease causation and to understand the effects of social structure on disease and health care in Haiti. In the present study, the concept alludes to the effects of the rigid Cambodian health care hierarchy on a new category of health personnel created ex nihilo by international HIV organizations. The hierarchy that determines socio-professional relationships and the authority of physicians over their patients is a characteristic common to biomedical services in general. Nevertheless, the foundations for hierarchical relationships depend on the specific social context (van der Geest \& Finkler, 2004). Our findings showed specific social forces which maintain the rigid local health care hierarchy: Volunteers hesitated to show any authority and most 
health planners and routine health personnel retained control over participation and silences volunteer voices. For many local players, their principle of hierarchy contrasts with the democratic values of the international vision of patient participation. These attitudes and visions which are not only the result of the strict health care hierarchy but which also support it, can be explained by cultural, historical, and political factors. Indeed, most of the literature on Cambodia highlights the rigidity of social relations.

For example, Guillou (2009) reminded her readers that the Cambodian society is divided into three principal social groups (peasants, businessmen, civil servants), and that depending on his or her social position, each person has strict codes to respect vis-à-vis his or her interlocutor. Peasants, who reflect the lowest class of the society are the most represented. As mentioned by Hugues and Un (2011), in $2006,80 \%$ of the population lived in rural zones and depended on agriculture. Being part of the peasant social class does not necessarily mean cultivating land but having a connection with a family in the countryside and making a personal and/or public contribution there. This study showed that most volunteers have such a link with a country family. People at this social position are used to adopting a behavior of "neak cuo": someone who does not question orders (Martin, 1989). Furthermore, the patronage system, which is widespread in South-East Asia, determines the socio-professional relationship, in which "clients" generally accept their hierarchical relationship with their "patron," as, in exchange for their submission, their employer provides protection, support, and assistance. Scott (1977) called this the "legitimacy of dependence." The choice by volunteers to adopt an attitude of withdrawal and non-contestation most of the time and prefer to submit to the hierarchical order, is in part linked to their social origin. Most national health planners and routine health personnel interviewed came from families of public servants or businessmen and were mostly from the high socio-economic classes, with well-to-do family backgrounds, and third-level education. This cultural explanation provides a static vision of the society where the lines demarcating different social groups are very clear, despite the reality being much more complex and fluid. Nevertheless, it reflects a general trend which must be taken into account to understand interactions in hospital hierarchy.

Historical factors must also be taken into account to understand this local relationship with hierarchy. In the past in Cambodia, where $90 \%$ of the population is Buddhist, volunteering traditionally involved a religious commitment at a pagoda ${ }^{10}$ (Mysliwiec, 2005). Villagers offered their help to pagoda organizations in a wide variety of activities of public utility, such as tree planting, drilling, road construction, and food production. Historical events have however long weakened these social links. During the rule of the Khmer rouge, volunteering meant killing other members of society. People were interrogated, encouraged to inform on others, and forced to confess to imaginary crimes. Families were displaced, with men, women, and children separated and placed in different hard labor camps. This fed both the fear of committing oneself to public service and the lack of confidence in public authorities, something which was perceptible in the interviews with volunteers. Despite the fact that HIV organizations which employ volunteers generally see the process as a means of making a commitment to public service, in contemporary Cambodia it takes on another meaning: Although some volunteers interviewed chose to participate in providing health care from a sense of civic duty, volunteering was first and foremost a means of obtaining a job and an income. Accordingly, in HIV services, the citizen's commitment to society is rarely the driving force behind volunteering, and volunteering is in reality associated with belonging to a precarious socioeconomic status, or to put it more simply, having precarious employment. Although Cambodians started becoming involved in international organizations after 1991, the effects of the Khmer rouge regime were still vivid at the time of the present study, and the fact many that volunteers preferred to submit to local health planners' and routine health personnel practices, rather than asserting themselves publically, can be explained by the effects of these historical events.

The political context also helps us better understand this behavior of submission by PLHA workers. The gap between the population and the representatives of authority has long been documented (Chandler, 1998; Collins, 1998; Ebihara, 1968). Cambodians have lived under a succession of autocratic regimes, where opposition, still present at the end of this study, was not encouraged. In Cambodia, people in authority are not generally seen as trustworthy or as people who act for the greater good of the citizens. Furthermore, the general population fears them. As underlined by Arendt (1983), trust in the State would seem to be essential to enable political freedom to be exercised. Similarly, in the context of health, a lack of trust in people in authority (in this case, national health planners and routine health personnel) often came up in volunteers' accounts during this study.

These cultural, historical, and political factors helped us better understand the inherent conflict in the health care hierarchy and the structural violence it can produce for PLHA workers in Cambodia.

\section{Conclusion}

Patient participation is a malleable concept, with meanings and applications that vary according to the context. 
As Blondiaux (2008) said, "lay participation draws its strength from its vagueness, the diversity of possible uses, and the fact that it can be rooted in widely different types of action and reference systems" (p. 24). PLHA workers are a key human resource for the development of HIV services. However, they feel exploited and stranded in precarious working situations. Just as in other contexts, lay participation reinforces existing inequalities (Cooke $\&$ Kothari, 2001) and masks the centralization of power (Mosse, 1994).

For the moment, conflicting existing visions of hierarchy and the rules which legitimize power among local players in Cambodia impede empowerment of PLHA workers. As Kalinsky, Arrue, and Rossi. (1993) pointed out, "participation in health" is rarely just "in health." PLHA empowerment requires the transformation of an entire social system, with a disruption of values, social organization, and the legitimization of power, which is obviously a slow and meticulous process.

Patient participation has been interpreted differently in Cambodia, right from the beginning, with no consensus or precise policy implemented. We highlight the importance of prior discussion and agreement between health planners, routine health personnel, and PLHA workers involved in patient participation, about adopting a unified approach, thereby limiting the structural violence which PLHA workers face on a daily basis. Such a unified approach would enable health planners to create a real working environment for these new workers, using a vision of hierarchy shared by all the stakeholders involved. Taking account of routine health personnel's reflections on this issue would also appear essential. Lorig (2002) argued that, "Professionals must make it clear that they want patients to become expert patients. Without proactive endorsement by the physician, patients cannot embrace their new role" (p. 815). The absence of a consensual social policy for PLHA workers has nonetheless helped health planners take advantage of a cheap labor source for the development of HIV services. However, at the time when this study was drawing to a close, this lay participation policy was at risk because of the departure of international organizations which have promoted and maintained these volunteer PLHA. The latter will have at least played a key role during the critical access to treatment scaling-up period (which coincides with the period of this study) when HIV care was decentralized in Cambodia to minimize the threat to lives.

\section{Acknowledgments}

I thank all the informants who gave up their time to this study, Frédéric Bourdier, my PhD advisor, and my colleagues Carine Baxerres, Fanny Chabrol, and Moritz Hunsmann for their helpful comments on a previous version. Finally, my thanks to Lisa Heseltine and Jude Sweeney for assisting me with the English translation.

\section{Declaration of Conflicting Interests}

The authors declared no potential conflicts of interest with respect to the research, authorship, and/or publication of this article.

\section{Funding}

The authors disclosed receipt of the following financial support for the research, authorship, and/or publication of this article: Support was received from the French National Agency for Research on AIDS (Grant ANRS 12133) and Sidaction (Grant BI19-3-01495).

\section{Notes}

1. During this study, we identified three categories of people living with HIV/AIDS (PLHA) participating at the hospital level (Mundul Mith Chuy Mith - which literally means "the centre of friends who helps friends"-coordinators, volunteers, and counselors) and three categories of PLHA working outside the hospital environment (employees of NGOs and networks, support groups, and home-based care leaders). For more information about the practices of the other categories, please refer to the following thesis by the first author (Bureau, 2010).

2. Ovesen and Trankell (2010) explained that "the exact number of people who died between 1975 and 1979 as a result of the Khmer rouge regime is impossible to determine. . . The various assessments by a number of demographers were summarized by Kiernan, who concluded that the death toll was between 1.671 million and 1.8 million" (p. 275).

3. The "continuum of care" is a guideline established by the Cambodian AIDS program in 2003 by international and national experts. Its purpose "is to plan the national approach to HIV care needs and to assist HIV/AIDS care managers and other key players to develop a continuum of care for PLHA at the local level which would provide comprehensive care within the existing health system (NCHADS, 2003, p. 6). This framework presents the different services to which PLHA should have access in public hospitals (voluntary confidential counseling and testing, biomedical, and psychosocial consultations, distribution of antiretrovirals and medicines for opportunistic diseases, prevention of mother-to-child transmission, and so forth), and the so-called "community" (home-based care teams, various AIDS NGOs, and support groups).

4. February 2006 to May 2006, September to December 2006, March 2007 to May 2007, October 2007 to April 2008.

5. Dr Frédéric Bourdier and Ayrine Uk were primary investigators for this study.

6. Civil disobedience alludes to the active, professed refusal to obey certain laws, demands, or commands of a government.

7. For further information on the findings of this larger study, please refer to the following report: Bourdier, Mom, Leang, and Seng (2009).

8. Twelve health planners were interviewed twice, 6 routine health personnel were interviewed twice, 25 PLHA workers were interviewed twice, and among the latter, 7 were interviewed a third time. 
9. In the sites where international workers were present on a daily basis, the working conditions of PLHA workers were generally better. However, at the time when this study was drawing to a close, all this was about to change as international workers were in the process of handing over their site to the Cambodian AIDS program.

10. Place of worship for those believing in Buddhism.

\section{References}

Arendt, A. (1983). La condition de l'homme moderne [The condition of modern man]. Paris: Calmann-Lévy.

Aveling, E.-L. (2010). The impact of aid chains: Relations of dependence or supportive partnerships for community-led responses to HIV/AIDS? AIDS Care, 22(Suppl. 2), 15881597.

Barbot, J. (2002). The sick in motion. Medicine and science tested by AIDS. Paris: Balland.

Bith-Melander, P. (2005). The role of women ant the rise of HIV/AIDS in Cambodia. Siksacakr, 7, 26-38.

Blondiaux, L. (2008). The new spirit of democracy. Current issues in participatory democracy. Paris: Seuil.

Bourdier, F., Mom, C., Leang, S., \& Seng, H.-S. (2009). L'éveil de la société civile dans la lutte contre l'épidémie à VIH au Cambodge [The rise of civil society in the fight against HIV epidemic in Cambodia] (Final Report). Paris: French National Agency for AIDS Research (ANRS).

Bureau, E. (2010). Anthropologie d'une norme globalisée. La participation profane dans les programmes de lutte contre le sida au Cambodge [Anthropology of a global norm. Lay participation in AIDS programmes in Cambodia] (Doctoral thesis). University of Victor Segalen Bordeaux-II, France.

Bureau, E. (2013). L'hôpital comme espace de circulation d'une norme globalisée. La participation des patients dans les services de lutte contre le sida au Cambodge [The Hospital as a Space for Circulation of a Globalized Norm: Participation of Patients in HIV Services in Cambodia]. Anthropologie et Sociétés, 37(3), 99-117.

Campbell, C., \& Cornish, F. (2010). Toward a "fourth generation" of approaches to HIV/AIDS management: Creating contexts for effective community mobilization. AIDS Care, $22,1569-1579$.

Chandler, D. (1998). A history of Cambodia (2nd ed.). Chiang Mai, Thailand: Silkworm Books.

Collins, W. (1998). Grassroots civil society in Cambodia. Phnom Penh, Cambodia: Center for Advanced Study.

Cooke, B., \& Kothari, U. (2001). Participation: The new tyranny. New York: Zed books.

Corbin, J., \& Strauss, A. (2008). Basics of qualitative research (3rd ed.). Los Angeles: SAGE.

Dudley, E. (1993). The critical villager: Beyond community participation. London: Routledge.

Ebihara, M. (1968). Svay, a Khmer village in Cambodia (Doctoral thesis). New York: Columbia University.

Epstein, S. (1998). Impure science: AIDS, activism and the politics of knowledge. Berkeley: University of California Press.

Farmer, P. (2003). Pathologies of power: Health, human rights, and the new war on the poor. Berkeley: University of California Press.
Fox, N. J., Ward, K. J., \& Rourke, A. J. O. (2005). The "expert patient": Empowerment or medical dominance? The case of weight loss, pharmaceutical drugs and the internet. Social Sciences \& Medicine, 60, 1299-1309.

Galtung, J. (1969). Violence, peace and peace research. Journal of Peace Research, 6, 167-191.

Glaser, B., \& Strauss, A. (1967). The discovery of grounded theory: Strategies for qualitative research. Chicago: Aldine.

Green, M. (2000). Participatory development and the appropriation of agency in southern Tanzania. Critique of Anthropology, 20, 67-89.

Guillou, A.-Y. (2009). Cambodge: Soigner dans les fracas de l'histoire [Cambodia. Providing care in the clashes of history]. Paris: Les Indes savantes.

HIV/AIDS Coordinating Committee. (2008, January-March). HIV/AIDS Coordinating committee network of NGO working on HIV/AIDS (Quarterly Report). Phnom Penh, Cambodia: Author.

Hugues, C., \& Un, K. (2011). Cambodia's economic transformation. Copenhagen, Denmark: NIAS Press.

Kalinsky, B., Arrue, W., \& Rossi, D. (1993). Health and social participation avenues: Institutional and historic signs. Buenos Aires, Argentina: Centro Editor de América Latina.

Kimerling, M. E., Schuchter, J., Chantol, E., Kunthy, T., Stuer, F., \& Glaziou, P. (2002). Prevalence of pulmonary tuberculosis among HIV-infected persons in a home care program in Phnom Penh. The International Journal of Tuberculosis and Lung Disease, 6, 988-994.

Lehmann, U., Van Damme, W., Barten, F., \& Sanderset, D. (2009). Task shifting: The answer to the human resources crisis in Africa? Human Resources for Health, 7, Article 49.

Lorig, K. (2002). Partnership between expert patients and physicians. The Lancet, 359, 814-815.

Marsland, R. (2006). Community participation the Tanzanian way: Conceptual contiguity or power struggle? Oxford Development Studies, 34, 65-79.

Martin, M. A. (1989). Le mal cambodgien [The Cambodian Harm]. Paris: Hachette.

Médecins Sans Frontières. (2006). Rapport d'activités 2005 [Activities report 2005]. Paris: Author.

Michaud, C. M. (2005). External resource flows to the health sector in Cambodia. Geneva, Switzerland: World Health Organization.

Micollier, E. (1999). L'autre: porteur originel et/ou vecteur privilégié du VIH-sida (Chine populaire-Taïwan) [The Other: Original carrier and/or main vector of HIV/AIDS (People's Republic of China-Taiwan)]. In C. Fay (Ed.), Le sida des autres: constructions locales et internationales de la maladie (pp. 73-86). Paris: Autrepart.

Morgan, L. M. (2001). Community participation in health: Perpetual allure, persistent challenge. Health Policy and Planning, 16, 221-230.

Morineau, G., Vun, M. C., Barennes, H., Wolf, R. C., Song, N., Prybylski, D., \& Chawalit, N. (2009). Survival and quality of life among HIV-positive people on antiretroviral therapy in Cambodia. AIDS Patient Care and STDs, 23, 669-677.

Mosse, D. (1994). Authority, gender and knowledge: Theoretical reflections on the practice of participatory rural appraisal. Development and Change, 25, 497-526. 
Mosse, D. (2004). Is good policy unimplementable? Reflections on the ethnography of Aid policy and practice. Development and Change, 35, 639-671.

Mysliwiec, E. (2005). Youth, volunteering and social capital in Cambodia: Results of a feasibility study conducted for a Cambodian youth service program. Phnom Penh, Cambodia: Youth Star.

National AIDS Authority. (2010). National AIDS Spending Assessment 2009-2010. NASA III Technical Validation Meeting, Phnom Penh, Cambodia.

National Center of HIV/AIDS, Dermatology and Sexually Transmitted Diseases. (2003). Cadre Opérationnel de la continuité des Soins pour les personnes vivant avec le VIH/ sida [Operational framework for continuum of care for people living with HIV/AIDS]. Phnom Penh, Cambodia: Author.

National Center of HIV/AIDS, Dermatology and Sexually Transmitted Diseases. (2008). Rapport annuel 2007. Phnom Penh, Cambodia: Author.

Nguyen, V. K. (2010). The republic of therapy: Triage and sovereignty in West Africa's Time of AIDS. Durham, NC: Duke University Press.

Olivier de Sardan, J.-P. (1995). La politique du terrain. Sur la production des données en anthropologie [The policy of fieldwork. On the production of data in anthropology]. Enquête, 1, 71-109.

Ovesen, J., \& Trankell, I.-B. (2010). Cambodians and their doctors: A medical anthropology of colonial and post-colonial Cambodia. Copenhagen, Denmark: NIAS Press.

Paxton, S., \& Stephens, D. (2007). Challenges to the meaningful involvement of HIV-positive people in the response to HIV/AIDS in Cambodia, India and Indonesia. Asia Pacific Journal Public Health, 19(8), 8-13.
Scott, J. (1977). Patron-client politics and political change in southeast Asia. The American Political Science Review, 66, 91-113.

Sopheab, H., Fylkesnes, K., Lim, Y., \& Godwin, P. (2008). Community action for preventing HIV in Cambodia: Evaluation of a 3-year project. Health Policy and Planning, 23, 277-287.

United Nation General Assembly Special Session. (2001). Declaration of commitment on HIV/AIDS. New York: United Nations.

United Nations Program on HIV/AIDS. (1999). From principle to practice. Greater involvement of people living with or affected by HIVIAIDS (GIPA). Geneva, Switzerland: UNAIDS Best Practices Collection.

van der Geest, S., \& Finkler, K. (2004). Hospital ethnography: Introduction. Social Sciences \& Medicine, 59, 1995-2001.

World Health Organization. (1978). Primary health care, Alma Ata. Geneva, Switzerland: Author.

World Health Organization. (2006). The world health report 2006: Working together for health. Geneva, Switzerland: Author.

World Health Organization. (2007). Treat, train, retain HIV/ AIDS: Task-shifting-Global Recommendations and Guidelines. Retrieved from http://www.who.int/health systems/TTR-TaskShifting.pdf

\section{Author Biographies}

Eve Bureau-Point, $\mathrm{PhD}$, is a social anthropologist, researching in the field of medical anthropology, post-doctoral researcher at the UMR 912, Marseille, France.

Sovannoty Phan, who has a master's degree in financial management from the Cambodian Royal University of Law and Economics, was a research assistant in this research project, at the UMR 912 in Marseille, France. 